\title{
School screening for scoliosis in Algiers. Results of a survey conducted in 1995-96 H Kaced* and H Belabassi
} \author{
Frères Halim, 16049, Douéra, Alger, Algeria \\ Email: H Kaced* - houria_kaced@live.com \\ * Corresponding author \\ from 6th International Conference on Conservative Management of Spinal Deformities \\ Lyon, France. 2I-23 May 2009 \\ Published: 14 December 2009 \\ Scoliosis 2009, 4(Suppl 2):OI doi:10.II86/1748-7|6I-4-S2-OI
}

Address: Service de Médecine Physique et Rédaptation Hopital de Douéra, Faculté de Médecine de Blida Alger Hopital Djillali Bounaama, Rue des

This abstract is available from: http://www.scoliosisjournal.com/content/4/S2/OI

(c) 2009 Kaced and Belabassi; licensee BioMed Central Ltd.

\section{Objectives}

The main aim of this study was to estimate the prevalence of Idiopathic Scoliosis among the Algiers school population. However, the analysis of the results also enabled us to sketch a profile of the typical Algerian child with scoliosis.

\section{Background}

The epidemiological profile of this disease has scarcely been studied in our country. In fact, management of Spinal Deformities was only effective in a few specialized centers in Algiers City, and thus all the patients with scoliosis who are diagnosed throughout the country had to move to the capital for treatment. Considering the frequency of severe deformities we had been treating, we deemed it important and urgent to focus our efforts on the timely detection of childhood curvatures before it becomes too late for conservative treatment

\section{Methods and results}

A screening survey for scoliosis was conducted on a sample of Algiers school children in 1995 - 1996. Our methodological steps corresponded to a prospective evaluation. It was based on a cross-sectional survey that had been executed in a restricted period and on a defined population where the information had been collected only once on each individual. In fact, 19,529 boys and girls, ages 5 to 16 years, were examined and $9.6 \%$ of them were referred to a specialized center because of their examination findings. The criteria for referral were mainly increased thoracic kyphosis, trunk rotation or spinal deviation in the coronal plane. Structural scoliosis was diagnosed in $25.35 \%$. The prevalence of Idiopathic Scoliosis (curves $>5^{\circ}$ ) was $2.38 \%$ with a female predominance; and the overall incidence of scoliosis of all types was $2.43 \%$.

\section{Outcome}

The Algerian Population has recently reached 33.8 million, with nearly $27.5 \%$ under the age of 15 . The considerable number of young people the Algerian population, along with the insufficiency of both specialized organizations or qualified teams skilled in the management of spinal deformities, induces us to emphasize the need for an early detection system for scoliosis at school. We felt that the epidemiologic data we obtained would show us the magnitude of the problem and obligate our ministry to act by changing the public health policies to react to the conclusions of our study. We expected that this study would supply some recommendations as to how to improve the training of school doctors and the specialists who are in charge of the orthopaedic pathology. We hoped it would lead to the identification of services for children with scoliosis and empower them to act, and we also hoped to develop the culture of multidisciplinary practice within our country.

\section{Conclusion}

This work resulted in recommendations that were not considered by our government until last year. At last, a 
program of school screening for scoliosis has become mandatory, just as the detection of defective vision, hearing problems or cardiac diseases has been. Currently, we are trying to organize some seminars about spinal deformity and its treatment. The management of all the students whose scoliosis will be detected by this program is yet another problem to consider.

Publish with Bio Med Central and every scientist can read your work free of charge

"BioMed Central will be the most significant development for disseminating the results of biomedical research in our lifetime. " Sir Paul Nurse, Cancer Research UK

Your research papers will be:

- available free of charge to the entire biomedical community

- peer reviewed and published immediately upon acceptance

- cited in PubMed and archived on PubMed Central

- yours - you keep the copyright

Submit your manuscript here:

http://www.biomedcentral.com/info/publishing_adv.asp 